\title{
O paradigma Cidade Jardim e o planejamento regional em Londres (1898 - 1944)
}

The City Garden paradigm and metropolitan planning in London (1898 - 1944)

El paradigma Ciudad Jardín y la planificación metropolitana en Londres (1898 - 1944)

CARMO, Julio Cesar Botega do ${ }^{1}$

1 Faculdade de Engenharias, Arquitetura e Urbanismo e Geografia, Universidade Federal de Mato Grosso do Sul, Mato Grosso do Sul, Brasil. juliobotega@yahoo.com.br ORCID ID: 0000-0003-0802-8393

Recebido em 15/04/2020 Aceito em 14/07/2020 


\title{
Resumo
}

As formas de planejamento regional de maneira recorrente se inserem na esfera das utopias. Das primeiras experiências, como o paradigma cidade-jardim às condicionantes que se apresentam hoje, tem sido alvo de diversas pesquisas e análises. Esse texto tem, portanto, caráter bibliográfico, onde, por meio da revisão da literatura e da consulta à fontes primárias, buscou-se entender o planejamento regional, e como este tem sido estudado sob diversos aspectos inclusive como a ideia de planejamento nesta escala circulou e foi incorporado aos estudos e legislação. Neste texto o objetivo é relacionar dito recorte de planejamento e sua relação com às ideias da cidade jardim, se atendo ao caso de Londres, onde o resultado foi a descentralização da metrópole e a aplicação do paradigma cidade-jardim cinquenta anos depois de sua criação.

Palavras-Chave: Planejamento Regional, Cidade Jardim, Londres, Howard, Abercrombie

\begin{abstract}
The ways of metropolitan planning are recurrently inserted in the sphere of utopias. From the first experiences, such as the city-garden paradigm to the conditions that are present today, it has been the target of several researches and analyzes. However, from the historiographical point of view, the method used in this research, the circulation of some ideas and concepts has not been explored as much, among them what we conventionally call metropolitan planning. Thus, the metropolitan has been studied under its economic, social, demographic, environmental aspects, among others, however, as the idea of planning on this scale circulated and was incorporated into studies and legislation, it remains a case to be studied in depth. In this text the objective is to relate this planning territorial delimitation, its origin and relation to the garden city, taking into account the British case.
\end{abstract}

Key-Words: Metropolitan Planning, Garden City, London, Howard, Abercrombie

\section{Resumen}

Las formas de planificación metropolitana se insertan recurrentemente en la esfera de las utopías. Desde las primeras experiencias, como el paradigma de la ciudad-jardín hasta las condiciones actuales, ha sido objeto de varias investigaciones y análisis. Sin embargo, desde el punto de vista historiográfico, el método utilizado en esta investigación, la circulación de algunas ideas y conceptos no se ha explorado tanto, entre ellos lo que convencionalmente llamamos planificación metropolitana. Por lo tanto, el área metropolitana se ha estudiado bajo sus aspectos económicos, sociales, demográficos, ambientales, entre otros, sin embargo, a medida que la idea de planificar a esta escala circulaba y se incorporaba a los estudios y la legislación, sigue siendo un caso para ser estudiado en profundidad. En este texto, el objetivo es relacionar este corte de planificación, su origen y relación con la ciudad jardín, teniendo en cuenta el caso británico.

Palabras clave: Planificación Metropolitana, Ciudad Jardín, Londres, Howard, Abercrombie 


\section{Introdução}

O início da problemática sobre o planejamento regional pode ser pontuado quando das primeiras discussões sobre as teorias regionais, especialmente os clássicos de Johann Heinrich Von Thunen (1783-1850), Ernest Burgess (1886-1966), Walter Christaller (1893 - 1969) e François Perroux (19031987). Elas serão formuladas durante o período que Sutcliffe (1984, p. 19) define como a "primeira era das metrópoles gigantes" Para compreender este objeto e suas relações com a sua região, além das teorias concebidas pelos geógrafos, economistas e sociólogos, Peter Hall (2013), entre outros autores, reconhece que o planejamento regional teve origem nos escritos de Patrick Geddes (1854-1932), biólogo britânico que influenciou de forma indelével a experiência norte-americana, seja via a Regional Planning Association of America (RPAA), ou por meio do Plano Regional de Nova York (PRNY), de Thomas Adams (1871-1940). Estes planos e teorias tem como semelhança a centralidade em uma metrópole. O estabelecimento de formas e modos de pensamento no século XIX foi de fundamental importância e influência no curso do planejamento regional e na transição do planejamento urbano das cidades medievais para modernas, onde se realizaram grandes intervenções urbanísticas.

As novas formas de crescimento da cidade deram origem ao planejamento regional, aplicado às maiores cidades ocidentais - em proporção, estruturas, funcionamento e qualidades. Este processo resultou na delimitação de regiões metropolitanas, a partir de 1953 como áreas de planejamento, sendo antecedidas por paradigmas que delimitaram e planejaram regiões e metrópoles.

Como afirma Ascher (1998) a metropolização não é exclusividade, nem imputável a determinado sistema econômico político, especificidades históricas ou políticas de privilegiamento de grandes cidades, tomando formas relativamente diversas. Contudo, o problema da responsabilidade sobre as áreas metropolitanas é mais complicado que o de sua delimitação ou planejamento. São áreas que se expandem e mudam continuamente, com limites pouco duráveis, o que lhes dá imagem de que são ingovernáveis. De forma a contornar tal problema, surgiram propostas para a institucionalização do fenômeno, que ocorre de acordo com Berger e Luckman (2004, p. 79) "sempre que há uma tipificação recíproca de ações habituais por tipos de atores (...) o que deve ser acentuado é a reciprocidade das tipificações institucionais e o caráter típico não só das ações, mas também dos atores nas instituições".

A teoria e a prática do planejamento são interpretadas e desenvolvidas por meio de fases, com um pacote de ideias distintas e dominantes, instituições e ideologias que se comprometem a explicar ou entender os desafios colocados naquele contexto. Deriva daí a noção de paradigmas, que organizados temporalmente, formam uma sequência didática ao estudo do planejamento, como o utilizado por Hall (2013) e Calabi (2012). O perigo é definir e presumir que uma definição particular de planejamento está restrita a um ponto no tempo e no espaço.

Neste sentido, a primeira fase do planejamento regional se caracterizou pelo estilo City Beautiful, logo conectado ao movimento da cidade-jardim, endereçados sobretudo aos subúrbios, em escalas locais ou regionais. Entre o século XVIII e XIX, nas origens do planejamento urbano moderno, o movimento City Beautiful imprimiu ritmo à discussão e extensão da reforma social e progressiva, em distintos locais, como nos Estados Unidos e Austrália. Suas características e uso foram uma ponte entre o legado da cidade antiga, as demandas da cidade industrial e o surgimento do planejamento regional como profissão, acompanhado da disseminação de controles de uso da terra e gestão sistemática do ambiente construído (FREESTONE; HAMNET, 2000). A partir da virada do século XIX para o XX o movimento se organizou, até mesmo de forma a pressionar o legislativo a respeito de suas demandas, que começaram a ser divulgadas para a sociedade por meio de associações e conferências. Planejavam-se as cidades principais, também denominadas metrópoles, criando planos de expansão e embelezamento. 
O crescimento urbano levou a reações às limitações e deficiências do paradigma City Beautiful, via Cidade-jardim e Planejamento Regional, influenciados pelos trabalhos de Howard $(1898 ; 1902)$ e Geddes (1994, publicado originalmente em 1915), centrados em temas como crescimento das grandes cidades, sua descentralização em unidades autônomas ou semiautônomas e sua relação com a região (CALABI, 2012). Se fortaleceram então novas condicionantes do crescimento urbano, como o zoneamento, transporte, habitação, entre outros, fazendo com que a partir de meados do século XX se deixasse de planejar apenas a expansão das cidades ou sua monumentalidade, mas também sua integração com os arredores, calcando-se em ideias de descentralização ou expansão da metrópole dentro da região.

A história do planejamento regional foi construída então sobre a evolução das regras econômicas, políticas, tecnológicas, culturais e ambientais, mais que de ações de intervenção. O planejamento e as legislações urbanísticas centraram-se na expansão das cidades, fundamentalmente no crescimento residencial, tendo como objetivo a criação de solo para a construção de habitações de forma a atender a demanda da população que se dirigia às cidades (CATALÁ, 2010).

Nesta pesquisa, pretendeu-se, ao recortar o tema, discutir como o ideário cidade-jardim foi utilizado para pensar a cidade de Londres (Reino Unido), a metrópole mundial do século XVIII à primeira metade do século XX, e que permanece como principal polo da rede urbana britânica, que teria influência na delimitação de regiões metropolitanas como áreas de planejamento. Considerando o planejamento um produto social, destaca-se a origem do ideário, agenda, evolução, formas e impactos de forma a não estar desvinculado de uma abordagem do contexto social no qual se desenvolveu. Sem este quadro, a história do planejamento poderia se degenerar em uma celebração de indivíduos, planos e lugares, com um simplismo e uma visão determinista, reificando planejadores e locais planejados (FREESTONE; HAMNET, 2000). Portanto, diferente de autores como Cullingworth e Nadin (2006), não cabe no escopo deste texto a comparação com o desenvolvimento do planejamento regional em outros países.

Definiu-se como ponto inicial o ano de 1898, fim de um século de intensas transformações, sobretudo no Reino Unido, local que precocemente sofreu com os problemas derivados do crescimento desordenado das cidades e da poluição das indústrias. Este ano foi marcado pela publicação do seminal texto de Ebenezer Howard, intitulado To-Morrow: A Peaceful Path to Real Reform, republicada em 1902 com o título (traduzido) Cidades-jardins do Amanhã, uma das principais e influentes obras da história do urbanismo e do planejamento.

Antônima ao crescimento, a baixa densidade foi o critério que, junto a outros, deu origem aos princípios da cidade-jardim como paradigma para superar as patologias e insalubridade urbanas geradas desde o início do desenvolvimento industrial. Acreditava-se que a baixa densidade especializa mais claramente o espaço e, no subconsciente coletivo, se associaria à cidade idílica, ao desfrute da paisagem e à integração da natureza na vida cotidiana (CALABI, 2012).

Neste texto, portanto, busca-se discutir as bases e o panorama londrino, suas especificidades, de forma a apreender sua complexidade, constrangimentos e desafios. Não é a pretensão construir um quadro exaustivo sobre as bases nas quais o planejamento regional foi pensado ou realizado de acordo com os paradigmas, mas ser sensível às restrições, aos casos específicos, aos períodos e políticas, que certamente foram influenciados pelo ideário. Nesse sentido, metodologicamente, a perspectiva historiográfica, a análise bibliográfica a partir dos documentos, planos e textos seminais sobre o período, oferece um caminho sistematizado para contribuir com o entendimento dos contextos e das mudanças na organização das sociedades, as políticas e o papel da profissão de planejador no período proposto. 
Nos anos 1920 os problemas de planejamento passaram a ser detectados em escala cada vez maior, levando à formação dos embriões de agências de planejamento regional direcionadas para a contenção do crescimento das cidades. As tentativas de planejamento nesse período, contudo, sofreram revés devido a queda da Bolsa de Valores de Nova York em 1929.

Como destaca Lucchese (2009), duas linhas de planejamento de destacaram no período. Além da cidade-jardim, os funcionalistas, que em 1933, resultante do quarto Congresso Internacional de Arquitetura Moderna, publicaram a Carta de Atenas com afirmações como "a cidade não é senão uma parte de um conjunto econômico, social e político que constitui a região" (CIAM, 1933, p. 1), e prosseguia colocando que "deve ser estudada em conjunto com a sua região de influência. O plano regional deve substituir o plano municipal. O limite da aglomeração será função do raio de sua ação econômica" (CIAM, 1933, p. 1).

Para a autora, é da miscigenação das duas propostas que foram criadas as novas cidades e repensada a própria Londres. Contudo,apesar da aderência dos funcionalistas, a escala metropolitana de preocupação se desenvolveu lentamente até o fim da Segunda Guerra e a maior parte das atividades de planejamento permanecia no nível local.

A reconstrução pós-Guerra, no entanto, reavivou o interesse em planejamento na maior escala principalmente com a construção de novas cidades na Grã-Bretanha e, mais tarde, em outros países, planejadas para realojar as populações deslocadas e ajudar a conter o crescimento das áreas metropolitanas estabelecidas.

A partir de então, o compromisso com a nova planificação e construção da cidade refletia e reforçava o planejamento na escala metropolitana. Vários planos metropolitanos foram realizados entre $1940 \mathrm{e}$ 1950, tendo como principais objetivos ordenar os padrões de uso da terra, especialmente em novas áreas de crescimento, e fornecer infraestrutura para o desenvolvimento. Os planos eram concebidos por profissionais especializados focados no nível do solo, por meio de controles de zoneamento necessários para garantir o desenvolvimento ordenado. Em termos gerais planejar neste momento, passou a ser percebido como um facilitador do crescimento econômico.

Tornou-se claro a partir nos anos 1940 que os Estados Nacionais deveriam assumir o protagonismo no desenvolvimento de infraestrutura e o resultado foi a profusão de serviços físicos e sociais e a preocupação com a terra necessária para o futuro crescimento urbano, bem como seu uso. Ou seja, um novo paradigma sistematicamente se instalou, superando os princípios da cidade-jardim e apontando para uma nova institucionalização do processo de metropolização, conformando as regiões metropolitanas. Com esse cenário, encerra-se o período estudado em 1944, ano de outra publicação importante na história do urbanismo britânico e para o ideário cidade-jardim, o Plano para a Grande Londres, de Patrick Abercrombie.

\section{O planejamento regional em Londres entre 1898 e 1944}

Como reação aos problemas da cidade do século XIX iniciou-se a história do planejamento moderno, ao mesmo tempo em que, de forma paradoxal, o objeto para a qual se buscava solução, também se modificava radicalmente. As raízes do planejamento regional remontam aos movimentos de saúde e de reforma de habitação britânico, quando os pensadores das cidades continuavam interessados pelos males da superpopulação e a cidade grande se transformava, devido à reação dos legisladores dos reformistas locais, das forças de mercado e das necessidades das diferentes classes sociais (BRESCIANI, 1984). 
A cidade dispersou-se e desconcentrou-se. Novas casas, fábricas, tecnologias de transporte, agências, melhores regulamentações do planejamento e desenvolvimento urbanos brecaram a superpopulação, resultando na melhoria dos padrões habitacionais. O crescimento residencial foi a forma mais conhecida, teorizada e estudada, sendo a base da modernização da cidade desde os fins do século XIX, início da urbanística moderna, passando pelos modelos utópicos, como os da cidade-jardim, de onde derivaria anos mais tarde o planejamento regional (HALL, 2013, p. 287).

Com este contexto, entre as experiências internacionais do ideário cidade-jardim, foram os britânicos que mais ousaram e colheram resultados (HALL, 2013), sendo expoentes deste movimento no país Ebenezer Howard, Raymond Unwin, Barry Parker e Patrick Abercrombie, entre outros.

O planejamento britânico surgiu, portanto, principalmente como reação aos problemas da cidade industrial não regulamentada, com suas altas taxas de mortalidade, disfunções sociais, oferta de habitação desigual e inadequada e a pobreza. Durante o século XIX a percepção dos problemas foi compartilhada entre as classes sociais, por meio de trabalhos como o de Engels (1844), proporcionando base sócio-política para o planejamento institucional. Neste sentido, a Grã-Bretanha passou a abordar a gestão urbana por meio do Town and Country Planning, com base na premissa de desenvolvimento da cidade e da região .

Esse planejamento emergente foi acompanhado por uma sucessão de campanhas de reforma que almejavam humanizar a Cidade Industrial, melhorando sua comodidade ambiental e sua funcionalidade. Seu objetivo imediato era trazer ordem espacial para as cidades vitorianas, atingindo durante o século XX padrões de desenvolvimento urbano e social que confrontavam os principais problemas. Os precursores pensavam as cidades por meio de propostas como a colonização planejada, o esquema de que quando uma cidade atingisse determinado tamanho dever-se-ia começar uma segunda separada da anterior por um cinturão verde, o desenho da praça central, das avenidas radiais e das indústrias periféricas que seriam a base do diagrama da cidade-jardim, a descentralização industrial de uma cidade superpovoada, a nacionalização da terra e seu caráter comunitário, projetos de cidades como elementos de um complexo regional, o impacto do desenvolvimento tecnológico sobre a localização das indústrias, entre outras.

Sobre estas bases se destacou Ebenezer Howard. Suas ideias foram desenvolvidas na Londres de 1880 e 1890, época de intensos debates sobre as cidades. O que Howard fez foi combinar de forma única as propostas, ainda que sua ideia inicial fosse mais mercadológica do que uma solução social (CALABI, 2012).

$\mathrm{Na}$ concepção howardiana, as influências rurais neutralizam a cidade e vice-versa, levando à importância simbólica dos espaços verdes (CALABI, 2012). A raiz de sua proposta era a imagem que se tinha do campo, um sentimento de democratização de uma área até então reservada à elite aristocrática e a classe média alta. A cidade-jardim de Howard teria um limite fixo, ao seu redor um cinturão verde e quando atingisse o limite planejado, então se desenvolveria outra cidade, a pouca distância dali.

Com o tempo, desenvolver-se-ia um vasto e planejado conglomerado que entraria num processo de expansão quase sem limites, ligado às demais por um sistema de transportes, o que proporcionaria as oportunidades econômicas e sociais da cidade grande. Esse conglomerado de cidades-jardim, e não a cidade-jardim individual, é que constituiria a realização física da cidade-campo.

O esquema proposto por Howard (1898) era de uma cidade social (figura 1), que ocuparia em rede uma área equivalente à da região de Londres, constituída de sete cidades com população máxima total de 250 mil habitantes. Após a publicação de seu livro, Howard tomou a iniciativa de organizar a Garden 
City Association para discutir suas ideias, e formular um esquema prático baseado nas linhas do projeto com todas as modificações que parecessem desejáveis.

Figura 1: A cidade Social de Ebenezer Howard



Fonte: HOWARD, 1898

A partir de sua criação, a Garden City Association teve como objetivos não só a construção de novas cidades em distritos rurais, mas também a criação de subúrbios-jardim assentados em princípios similares que desafogassem as cidades existentes e alojassem adequadamente as classes trabalhadoras perto de seus empregos (HALL, 2013).

Era o Estado então o planejador regional por se envolver com a programação e o financiamento da infraestrutura pública. Na Inglaterra, em 1855 criou-se o Conselho do Condado de Londres (LCC), que pressionou o Parlamento até conseguir em 1900 que se aprovasse uma emenda que lhe permitia construir grandes conjuntos de "habitações para a classe trabalhadora" nos limites do Condado e para além deles, o que fez com que se iniciasse a construção de conjuntos, ainda que uma Comissão Real recomendasse que as classes trabalhadoras fossem realocadas no centro (HALL, 2013). A receita do LCC deu certo, com as famílias deixando as superlotadas habitações coletivas e trocando-as por casas nos arredores da cidade. Contudo, houve um caráter socialmente seletivo dessa migração, fazendo com que o problema da superlotação piorasse.

De forma precoce, a capital e outras grandes cidades britânicas passaram pela era da suburbanização em massa depois da Primeira Guerra Mundial (figura 2). A chave foi o transporte, pois as urbanizações implantavam-se a uma distância que impossibilitava a ida a pé para o trabalho, acarretando o aparecimento do bonde e em seguida dos ônibus intermunicipais, permitindo o crescimento da construção habitacional com fins lucrativos ao redor das grandes cidades e dependentes de transporte. O potencial comercial na ocupação de solo que acompanhava as novas linhas de trens e bondes levou à noção de que era atribuição do empreendedor a instalação destas, para que em torno delas se desenvolvessem os subúrbios, uma vez que transporte e moradia expandiam a mancha urbana. Esta 
concepção se manteve até que o poder público se deu conta que obras públicas diminuem o desemprego, assumindo tal demanda (HALL, 2013).

Figura 2: Expansão da mancha urbana de Londres (1784-1939)



A urbanização tomou duas formas, primeiro a de explosão da construção com fins lucrativos; segundo a de uma grande expansão das áreas residenciais construídas pelas autoridades locais, sobretudo em torno das grandes cidades, e geralmente sob a forma de cidades-satélites dependentes. Com frequência o subúrbio de finalidade lucrativa era destituído de todo e qualquer plano abrangente, desenvolvendo-se à medida que se abriam ruas de vários construtores até que a terra acabasse, resultando em casas isoladas, semelhantes e distantes de serviços. As casas eram projetadas sem preocupações com planejamento, então o resultado dependia do que se podia por ele pagar. Ambas as formas acabaram sendo condenadas por falta de planejamento, fortalecendo a necessidade de um sistema mais eficaz, até que em 1920 o Royal Institute of British Architects baniu a prática da arquitetura com fins lucrativos, promovendo a construção realizada por autoridade local (HALL, 2013).

Contemporâneo a Howard, Raymond Unwin (1863-1940) foi outra figura de destaque para o movimento cidade-jardim e o planejamento regional na Grã-Bretanha. Foi com ele e Barry Parker (1867-1947) que os projetos cidade-jardim começaram a ter realização física, com projetos icônicos 
como os de Letchworth e Hampstead, que significaram mudanças para o movimento, pois se propunha não apenas cidades-jardim, mas também subúrbios-jardim.

Durante a Primeira Guerra, Unwin foi indicado para o Comitê da Habitação, apresentando um relatório em 1918 que constitui um dos documentos que mais influiu no desenvolvimento das cidades britânicas do século XX. Este possuía quatro propostas:1) somente as sociedades de utilidades públicas poderiam executar a tarefa de construir casas; 2) as autoridades locais deviam construir em terra barata e não urbanizada, tendo o cuidado de desenvolver seus projetos por etapas e paralelamente à instalação progressiva dos bondes; 3) densidades máximas de doze casas unifamiliares por acre ${ }^{1}$ e; 4) as plantas deveriam ser elaboradas por arquitetos (UNWIN, 1912).

A partir deste documento, as Legislações locais restritivas foram superadas pela utilização de poderes parlamentares especiais. Calabi (2012) destaca que no período entre guerras o debate sobre a reconstrução se deu entre os que a defendiam de acordo com os princípios originais do movimento cidade-jardim e aqueles que sugeriam a adaptação dos princípios às novas condições urbanas. Havia dois grandes remédios: construir verticalmente ou mudar. O primeiro era impraticável para uma população de trabalhadores, pois para os defensores da cidade-jardim era a casa independente que os atraía. Era essencial então estabelecer um plano integrado para a urbanização de toda a área construída de Londres, o que levou no ano seguinte, em seu relatório final, o Comitê reiterar essa última recomendação, solicitando recursos ao governo a fim de dar início à construção das cidades.

Unwin recomendara a construção de "cidades-satélites" próximas dos municípios, espécies de subúrbios-jardim dependentes, para a obtenção de empregos. Em 1918, integrante do Comitê Tudor, fez constar essa recomendação para o programa de habitações populares no pós-guerra, o que ocasionou a construção de um milhão de moradias populares subsidiadas, nenhuma obedecendo à forma cidade-jardim. O problema da habitação para as classes trabalhadoras tornou-se então responsabilidade pública, sendo as moradias construídas sob forma de satélites nas periferias das cidades, onde os subúrbios cresceram quase ao ponto de formarem novas cidades. Foram construídas, obedecendo a Unwin, como satélites periféricos ao invés de cidades-jardim independentes. Este impulso à melhoria dos padrões habitacionais favoreceu os não realmente pobres, impossibilitados de arcar com a dupla carga de aluguel mais condução, além de fazer os defensores puristas das cidades-jardim sentirem-se traídos (HALL, 2013).

O país conseguiu cidades-satélites, a construção de cidades novas teve um atraso de trinta anos e a capital permaneceu com seu problema habitacional (HALL, 2013). Unwin pode, entretanto, demonstrar aquilo que publicara em Notthing Gained by Overcrowding! (1912), que um esquema adequado de planejamento poderia propiciar a todos muito mais espaço sem usar mais terreno. As urbanizações deveriam assumir a forma de satélites semiautônomos e não de cidades-jardim independentes, rompendo com a cidade-jardim em estado puro.

O antigo parceiro de Unwin, que retornara após o término da Primeira Guerra, Barry Parker, projetou Wytenshawe em 1927, onde introduziu três princípios do planejamento norte-americano, extraídos da região de Nova York. O primeiro foi o de unidade de vizinhança. O segundo o princípio do esquema Radburn, que Clarence Stein e Henry Wright haviam desenvolvido em seu plano para a cidade-jardim de mesmo nome. O terceiro é o princípio do parkway, combinada com as estradas ajardinadas, concebidas por Frederick Law Olmsted e amplamente utilizadas pelos planejadores filiados à tradição City Beautiful no início do século. Ou seja, as parkways como vias de acesso às áreas residências ligadas aos parques públicos, elemento essencial do plano cidade-jardim, não destinados exclusivamente à recreação e sendo usadas por todo tipo de veículo.

\footnotetext{
${ }^{1}$ Medida ainda utilizada por algumas das antigas colônias do Império Britânico. Um acre equivale a 4042 metros quadrados.
} 


\subsection{Conquistas do planejamento regional via cidade-jardim em Londres}

Em 1937, chegou ao poder Neville Chamberlain, o qual pôs em atividade uma Comissão Real para a Distribuição Geográfica da População Industrial, presidida por Sir Anderson Montague Barlow. A Comissão Barlow chegou à conclusão que se Londres crescesse além de doze a quinze milhas estabelecido pelo sistema de metrô, necessariamente deixaria de ser Londres, um conceito unitário, ou seja, a metrópole precisava parar de crescer. Seria possível continuar implantando indústrias e depois residências, e a seguir novamente indústrias e novamente residências, construindo indefinidamente, mas isso já não seria Londres. Daí ter preconizado não só a fixação de um cinturão verde, mas também o controle sobre a implantação das indústrias na região londrina (HALL, 2013).

Tão logo Chamberlain criou a Comissão Barlow, Unwin, em 1938, argumentou que a grande contribuição de Howard fora o subúrbio-jardim e não a cidade-jardim; urbanizações sob forma de satélites constituiriam proteção suficiente contra a incessante expansão de Londres. A única saída para a situação, segundo ele, era constituir uma Comissão para o planejamento regional de Londres com poderes de organizar juntas executivas encarregadas de construir novas cidades ou expandir as existentes, bem como de descentralizar a indústria e o comércio dentro de uma região ampliada.

Patenteava-se a visão de uma conurbação gigantesca, organicamente planejada, na qual um único sistema de transporte coletivo e integrado forneceria a estrutura, e o planejamento do uso do solo guiaria o crescimento. Até então, planejamento regional na Grã-Bretanha era inexistente e a Comissão Barlow aceitou o que ele disse. Isso mudaria a forma de se planejar a região da metrópole, levando ao Plano de Abercrombie, em 1944, o qual assinala em inúmeras passagens a influência e o uso dos dados elaborados pelo relatório da Comissão (ABERCROMBIE, 1944).

A proposta de construção de cidades novas pretendia ser uma alternativa ao morar na metrópole. Elas deveriam permanecer dentro de um tamanho limite, como a Town and Country Planning Association dissera; deveriam ser construídas por corporações estatais e financiadas pelo poder público, resolvendo o problema de como conseguir financiar as novas cidades, ao mesmo tempo em que destruía com a essência coletivista do plano de Howard. O planejamento de cima para baixo levou a melhor; da visão howardiana de cidade-jardim, a Inglaterra ficaria apenas com a superficialidade (HALL, 2013).

Após a Segunda Guerra, o governo formou uma Comissão para erguer as novas cidades, das quais oito foram construídas nos arredores de Londres, seguindo quase todas as prescrições do plano de Abercrombie (figura 3). Na reedição da publicação de Howard realizada por Osborn (1965), este inseriu no capítulo 13 do original a mesma imagem, destacando que ela contém as ideias cidade-jardim aplicadas à Londres, os sítios sugeridos para as novas cidades e as cidades-jardim já implantadas, bem como o cinturão verde proposto por Abercrombie em 1944. 
Figura 3: Princípios cidade-jardim aplicados à Londres no plano de Abercrombie (1944) de acordo com Osborn (1965)

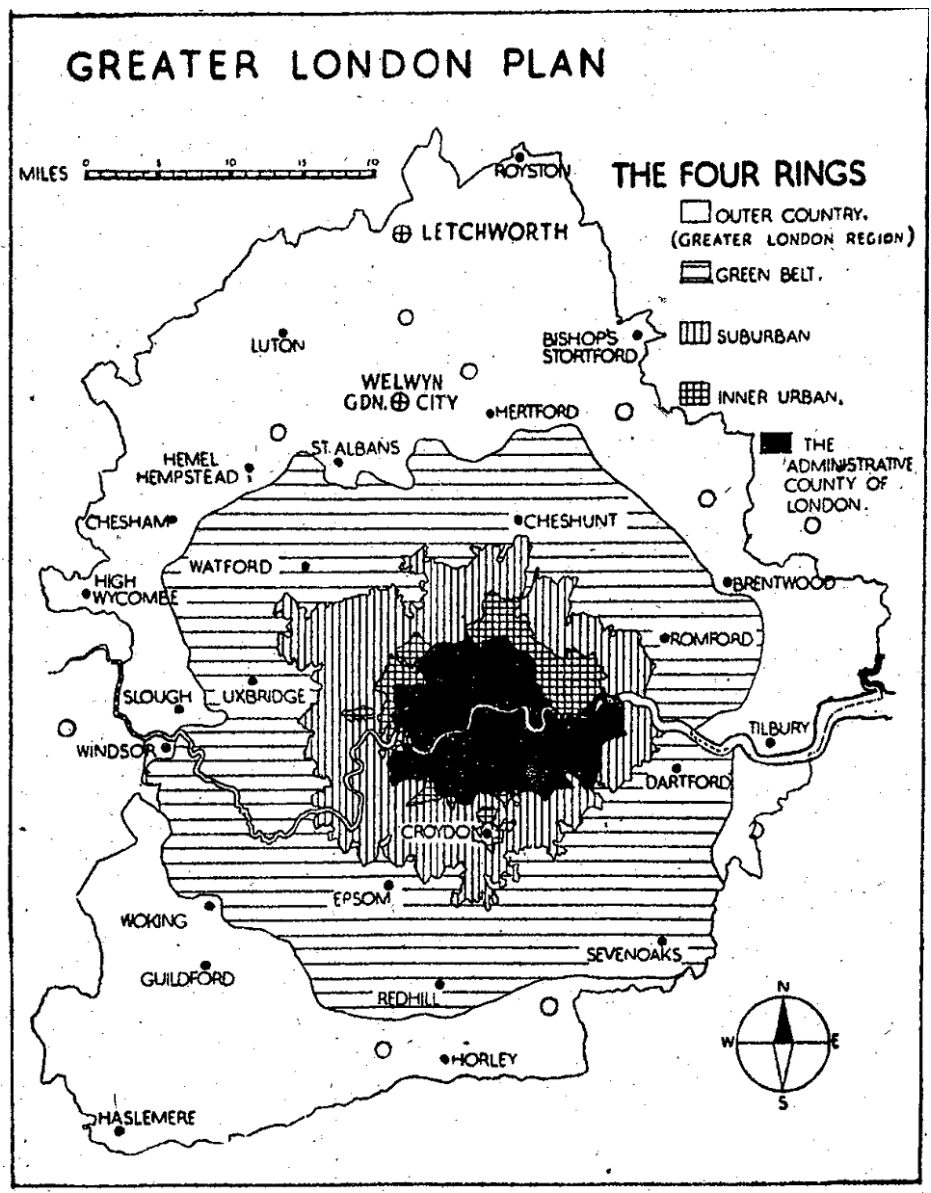

$\oplus$ Letchworth and Welwyn Garden Cities

O Proposed sites for new "satellite" towns in Plan.

Fonte: ABERCROMBIE (1944); HOWARD; OSBORN (1965)

Em 1946, a Lei das Novas Cidades recebeu a sanção real; em novembro a primeira, - Stevenage, entre Welwyn e Lechtworth - foi designada, dando início a descentralização da região metropolitana de Londres. Até 1950 o governo trabalhista determinou treze novas cidades: oito na área londrina, duas na Escócia, duas no Nordeste, uma no interior da Inglaterra e uma em Gales (figura 4). Cada cidadejardim circundada por seu próprio cinturão verde, ligadas entre si e também ao centro de Londres. As novas cidades eram parte importante de sua ideologia. 
Figura 4: Cidades novas como estratégia de descentralização metropolitana do Reino Unido em 1969

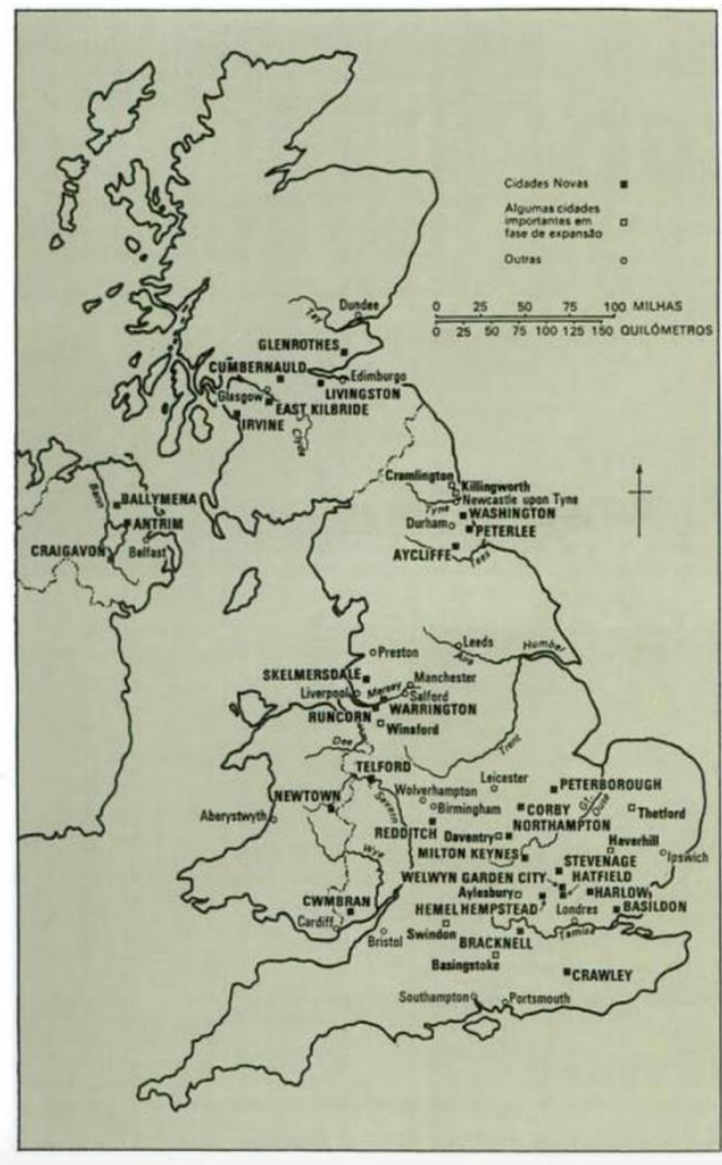

Fonte: HOWARD, 2002, p. 87

O fato é que no processo, muita coisa se ganhou e alguma se perdeu. Na terra onde foi concebida, a cidade-jardim via-se agora nacionalizada e burocratizada (HALL, 2013). Se o persistente problema habitacional de Londres continuava, passado meio século, e se era preciso evitar os erros cometidos entre as duas guerras, o plano de Abercrombie se pretendia resistente e flexível, capaz de passar por cima de interesses locais específicos se necessário. Foi o que o governo fez, fortalecendo o planejamento regional comoparadigma para pensar as metrópoles.

\section{Considerações Finais}

Para Calabi (2012), a obra de Howard permanece como marco inicial de uma das mais relevantes linhas teóricas do urbanismo, como alternativa ao crescimento contínuo da metrópole. As cidadesjardim seriam colônias das metrópoles, autogovernadas, com propriedade coletiva do solo e com tamanho máximo de crescimento. Seu intento não era confinar as pessoas em pequenas cidades, mas planejar conurbações com centenas de milhares, quiçá milhões de habitantes. Não se tratava de planejamento físico, mas veículos para a reconstrução progressiva da sociedade capitalista dentro de uma infinidade de comunidades cooperativas. Não via as cidades-jardim como colônias para pobres, mas fundadas e administradas pela classe média, que se livraria dos cortiços urbanos e se afastaria do alcance da fumaça de Londres (HALL, 2013). 
As tentativas de modificação a partir do deslocamento de residências deram lugar à descentralização das indústrias na segunda metade do século XX, com novas regulamentações metropolitanas e que tiveram o Town and Country Planning como direção. O "ordenamento do território" obteve forma institucional (por meio de legislação e organização profissional), e o modelo passou a contar com mecanismos de regulação para atingir o seu fim principal - o desenvolvimento das cidades. Anteriormente, iniciativas utópicas com base em intervenções, tais como a criação de cidades ideais e subúrbios, foram ultrapassados por um regime institucional encontrado no controle legal para guiar o desenvolvimento.

Após a Segunda Guerra Mundial a ênfase passou para as condições de crescimento e como estas contribuem para a contínua suburbanização (descentralização). A era de projetos de subúrbios se enfraqueceu e o poder econômico e político nas cidades passou a explorar com particular atenção o conjunto de atores e interesses que interagem para moldar a política e o ambiente construído de novas cidades.

No outro lado do Atlântico, nos Estados Unidos, em 1947 criou-se o termo região metropolitana, enquanto em 1954 no Canadá se delimitou a primeira região metropolitana que desde 1953 tinha uma agência que regulava seu crescimento e desenvolvimento. As regiões metropolitanas se tornaram a síntese, uma unidade de planejamento, de aplicação do Town and Country Planning, o que levou alguns autores a definirem o período entre 1940 e 1970 como o primeiro período de planejamento das regiões metropolitanas.

Conclui-se que o legado das cidades-jardim para o planejamento regional reside no pensar os subúrbios e as novas cidades, bem como nas ideias normativas sobre as características do espraiamento metropolitano, sua extensão horizontal, a gestão do crescimento, a eficiência e a economia. Foi a era dos pioneiros, os primeiros a realizarem legislações com exercícios de planejamento regional compreensivo, daí a importância que adquiriram para os interessados em compreender as origens e formas de pensar o planejamento das metrópoles e regiões metropolitanas.

\section{Referências}

ABERCROMBIE, Patrick. Greater London Plan. Londres, His Majesty's Stationery Office, 1944.

ASCHER, François. Métapolis: acerca do futuro das cidades. Oeiras, Ed. Celta, 1998.

BERGER, Peter L.; LUCKMANN, Thomas. A construção social da realidade. Petrópolis, Vozes, 2004.

BRESCIANI, Maria Stella Martins. Metrópoles: As faces do monstro Urbano (as cidades no século XIX). Revista Brasileira de História. São Paulo: ANPUH. set./abr, 1984.

CALABI, Donatella. História do urbanismo europeu: questões, instrumentos, casos exemplares. São Paulo: Perspectiva, 2012.

CATALÁ, Rafael García. Crecimiento Urbano y el Modelo de Ciudad. ACE: Arquitectura, Ciudad y Entorno [on-line]., Ano 4, núm. 12 Fevereiro. P. 159-167, 2010. Disponível em https://upcommons.upc.edu/bitstream/handle/2099/8557/ACE_12_SN_40.pdf?sequence=7 acesso em julho de 2015.

CIAM. Carta de Atenas. 1933. Disponível em http://portal.iphan.gov.br/uploads/ckfinder/arquivos/Carta\%20de\%20Atenas\%201933.pdf acesso em março de 2016. 
CULLINGWORTH, Barry; NADIN, Vincent. Town and Country Planning in the UK. Routledge, 14 ed., Londres, 2006.

ENGELS, Friedrich. A Grande Cidade. In: ENGELS, F. A situação da classe trabalhadora na Inglaterra. São Paulo: Boitempo, p. 67-116, 2008

FREESTONE, Robert; HAMNETT, Sthefhen. (Eds). The Australian Metropolis. Sydney, Allen and Unwin, 2000.

GEDDES, Patrick. Cidades em Evolução. Campinas, Papirus, 1994.

HALL, Peter. Cidades do Amanhã - Uma história intelectual do planejamento e do projeto urbanos no século XX. São Paulo, Perspectiva, 2013.

HOWARD, Ebenezer. To-Morrow: A Peaceful Path to Real Reform. Londres, Swan Sonnenschein \& Co, 1898.

LUCCHESE, Maria Cecília. Em defesa do planejamento urbano: ressonâncias britânicas e a trajetória de Harry James Cole. Tese (Doutorado em Arquitetura e Urbanismo), USP, São Carlos, 2009.

OSBORN, Frederick J. Introdução. In: HOWARD, Ebenezer. Garden cities of Tomorrow. Londres, Faber \& Faber. 1965, publicado originalmente em 1902.

SPOSITO, Maria Encarnação Beltrão. Capitalismo e Urbanização. 3. ed. São Paulo: Contexto, 1991. SUTCLIFFE, Anthony. Metropolis 1890-1940 Mansell, London, 1984.

UNWIN, Raymond. Nothing Gained by Overcrowding! How the Garden City Type of Development May Benefit Both Owner and Occupier. 1912. P. S. KING \& SON, Orchard House, Westminster, the Garden Cities \& Town Planning Association. Disponível em http://www.tcpa.org.uk/data/files/Nothing_Gained_By_Overcrowding.pdf acesso em julho de 2015. 